\title{
¿Cómo cambia la comunicación política? Reflexiones y tendencias a partir de las experiencias de América Latina ${ }^{1}$
}

\author{
How does Political Communication Change? \\ Reflections and Trends Based on Latin American \\ Experiences
}

Ismael Crespo Martínez

Recepción: 28 de Agosto de 2015

Aceptación: 4 de septiembre de 2015

\section{Resumen}

Este texto tiene como objeto analizar los cambios que se están produciendo en la comunicación política que se desarrolla en el marco de las campańas electorales, en especial, pero no solamente, a la luz de las recientes tendencias en diversos países de América Latina y, en menor medida, Europa. La argumentación sobre estos cambios se estructura en diez reflexiones, que fundamentadas en investigaciones previas tanto del autor como de otros investigadores, han podido ser percibidas y contrastadas sobre el terreno, a partir de la experiencia personal como consultor para gobiernos, partidos políticos e instituciones con función ejecutiva.

Palabras clave: comunicación política, América Latina, campañas, elecciones.

\section{Abstract}

This document is aimed at analyzing the changes occurring in political communication within the context of election campaigns, especially, but not only, under recent political trends in different Latin American countries and, to lesser

1 Las primeras ideas para elaborar este texto fueron expuestas durante el IV Congreso Uruguayo de Ciencia Política, celebrado en Montevideo del 14 al 16 de noviembre de 2012. Una versión elaborada se presentó posteriormente en las II Jornadas Espańolas de Ciberpolítica, organizadas por Ramón Cotarelo en el Centro de Estudios Políticos y Constitucionales de Madrid, el 27 de mayo de 2013. El marco para realizar esta investigación es el Proyecto La Ideología Política en las Campańas Electorales: Europa y América Latina en perspectiva comparada, financiado por el Plan Nacional de Investigación Científica, Desarrollo e Innovación Tecnológica (CSO 2012-36759). 
extent, in Europe. There are ten reflections about these changes, which grounded in previous research both from the author and form other researchers, have been perceived and proven in situ, based on a personal experience as a consultant for governments, political parties and institutions with executive function.

Keywords: political communication, election campaigns, Latin America, elections. 


\section{Introducción}

ste texto tiene como objeto analizar los cambios que se están produciendo en la comunicación política que se desarrolla en el marco de las campañas electorales, en especial, pero no solamente, a la luz de las recientes tendencias en diversos países de América Latina y, en menor medida, Europa. La argumentación sobre estos cambios se estructura en diez reflexiones, que fundamentadas en investigaciones previas tanto del autor como de otros investigadores, han podido ser percibidas y contrastadas sobre el terreno, a partir de la experiencia personal como consultor para gobiernos, partidos políticos e instituciones con función ejecutiva. Los diez argumentos presentados tienen formato de tendencias y, en algún caso, de predicciones a corto plazo. Parten de una revisión de los modelos tradicionales, acotan en algún caso la situación en el presente y presentan las tendencias que la comunicación de campaña tendrá en un futuro cercano.

Es más que posible, que los lectores conocedores del terreno que aborda este artículo, perciban que algunas tendencias son ya realidades, con más o menos intensidad según los países donde se sitúe la mirada. Esto es así porque la actual comunicación política y de campaña está inserta en un escenario que muta y se transforma a gran velocidad, impulsado por el cambio constante de las herramientas e instrumentos que proveen las nuevas tecnologías de la comunicación; por los cambios acelerados en unas sociedades en profunda transformación, y por unos partidos políticos que perciben como nunca que la vieja política se resquebraja a marchas aceleradas. He aquí las reflexiones y tendencias de cambio que se anotan para el escenario de esta década.

\section{En la competición electoral, los partidos (estructuras) ceden los espacios de comunicación a sus líderes (personas)}


Desde fines de los años 60, tras los procesos de crisis partidista tanto en Europa como en América Latina, y de manera más aguda a partir de la caída del Muro, la debilidad de los partidos políticos y el declive de las lealtades e identificaciones partidistas de la ciudadanía, han conjurado a favor de una personalización cada vez más notable de las prácticas comunicacionales en el marco de las campańas electorales. El modelo de campaña "presidencialista", que se impone incluso entre los regímenes parlamentarios, está siendo reforzado tanto por efecto de las coyunturas críticas, como las crisis económicas en Europa o la falta de institucionalización de los sistemas de partidos en América Latina, como por la ola de desafección y falta de confianza y credibilidad que se impone entre los ciudadanos hacia sus partidos e instituciones. La espiral de fomento de la aversión a todo lo relacionado con la política tradicional y los "viejos" partidos, propicia el surgimiento de nuevas formas de hacer y comunicar política basadas en la personalización (Guerrero y Manzano, 2013: 69).

La personalización es parte intrínseca de la comunicación política moderna ${ }^{2}$. La penetración en los sistemas democráticos, tanto presidencialistas como parlamentaristas, de las prácticas y rutinas de comunicación política desarrolladas en Estados Unidos, ha provocado la transformación del escenario de las estrategias comunicativas en el marco de las campañas electorales (Sánchez Medero, 2009). A éstas se ha trasladado un modelo de comunicación y propaganda persuasiva centrado no en la identificación de los ciudadanos con los partidos y/o las ideologías (Sánchez Galicia, 2010), sino en la acción política en los medios de comunicación, en especial en la televisión; la desaparición de la imagen de los partidos en favor de la de su líder o candidato, y la desideologización de los programas electorales (Sánchez Medero, 2009). El líder o

2 Aunque el proceso de personalización se ha acentuado con las características de la comunicación política moderna, no debemos obviar que esto no es un proceso nuevo. Podemos encontrar las primeras escenificaciones de la personalización de los líderes en el culto a la imagen personal del líder mediante estatuas, uso de retratos personales o acuñación de monedas (Dader, 1990). Así, no se puede ligar la personificación de la política como un instrumento atribuible únicamente a la postmodernidad ni a las sociedades democráticas (Gómez et al., 2006). 
candidato ha pasado a convertirse en un factor decisivo de voto, siendo esto más evidente en las campañas por la relección, donde el partido anula su presencia en favor del presidente o primer ministro saliente y candidato a una nueva nominación.

Esto no quiere decir que los partidos estén al margen de este proceso. Al igual que los ciudadanos o los medios de comunicación, los partidos son promotores de esta personalización, pues les sirve como una herramienta diferenciadora de los otros partidos. Quedará pues una política de comunicación que respetando las seńas de identidad partidista se oriente a unos públicos más alineados, favoreciendo la forma tradicional de comunicación basada en la identidad corporativa (Crespo y Carletta, 2013: 86-87), y otra forma, más postmoderna, en la que en el contexto de una política personalizada, el mensaje hacia los electores será encomendado a los líderes y candidatos, que además de ser portadores de la oferta electoral del partido, deberán esforzarse por hacer ésta creíble y ellos en sí mismos confiables. Por ello, el líder o candidato debe actuar no sólo como componente emocional del programa electoral, sino como elemento social (Canel, 2006: 48-50). Como expone Bauman (2002: 77-78), los candidatos dejan de ser meros transmisores de los mensajes para ser "ejemplo y guía", siempre que exista una identificación del ciudadano y una confianza de éste hacia el portador del mensaje.

Una acusada personalización de la campaña, como sucede en muchas de las recientes elecciones en América Latina, pero también en algunos casos de Europa, puede llevar al candidato a generar su propia marca, autónoma de las siglas y símbolos tradicionales de su partido. Esta marca en muchas ocasiones le identifica a él por encima de la del partido, e incluso en otras puede llegar a anular por completo las siglas del partido. Si hace cuarenta años no podíamos entender una campańa sin partidos, hoy en muchos lugares no comprenderíamos una campaña sin un candidato-marca. El posicionamiento de una marca propia del candidato permite a los ciudadanos identificarse de una manera más sencilla (casi intuitiva) con las ideas y la personalidad (atributos) del 
líder o candidato. La creación de la marca Obama, como ejemplo de un branding político exitoso, o en el caso de España la creación de la marca "ZP" (o los casos de "Lula" en Brasil, los "K" (Kirchner) en Argentina o la "U" de Uribe en Colombia), provocaron que el resto de los actores políticos de la competición pasen a un segundo plano, permitiendo a los ciudadanos simplificar su decisión de voto, asociando la misma a las ideas y atributos representados en la marca política (García Jiménez, 2010: 46).

\section{El relato, el mito y la idea-fuerza se han convertido en ejes vertebradores de la comunicación política}

A partir de mediados de los años 60 , se fue consolidando un modelo anglosajón de marketing político-electoral tanto en Europa como en América Latina basado en una oferta partidista centrada en propuestas y políticas concretas, y que abandonó progresivamente las ideologías, las identidades, los valores y las cosmografías. Los partidos de centro-derecha se adaptaron rápidamente a este modelo, que comenzó a ser predominante. A finales de los años 80 , los partidos socialdemócratas también adoptaron esta estrategia, que alcanzó su apogeo durante la década de 1990. El fundamento de esta propuesta se sostenía sobre la idea de una participación electoral basada en modelos de decisión racional. El comportamiento de los que en este modelo pasarían a denominarse ciudadanos-clientes, no estaba sujeto a la influencia de las tácticas de persuasión tradicionales, sino a una elección meditada, estratégica y racional de cada individuo en función de criterios de coste-beneficio. La satisfacción de las necesidades objetivas de los electores (o clientes) sería la base del éxito de una campaña electoral (Martín Salgado, 2002: 52-54).

Sin embargo, a partir del siglo XXI, las lecciones aprendidas sobre la construcción de un eje temático que domine la campaña y marque sus tiempos para la entrada de los asuntos de interés en la arena de la competición empezaron a perder su relevancia. En Europa, pero sobre todo 
en América Latina, comenzó a surgir un pensamiento crítico que, inspirado en postulados de origen gramsciano (Mouffe, 2007), sostenía que la clave de la persuasión no radicaba en la satisfacción de las necesidades objetivas de los electores, sino en la construcción de relatos emotivos, apasionados, míticos, con una estructura de orden aristotélico ${ }^{3}$, cuya elaboración e instalación en la mente de los electores debería realizarse con mucha anterioridad al tiempo electoral ${ }^{4}$. En este nuevo modelo de marketing político, el relato comienza no sólo a asumir el papel que tradicionalmente había jugado el eje temático, sino que también se convierte en el marco para la elaboración del discurso político. Cuando llega el periodo electoral, el relato debe estar ya instalado en los cerebros de los públicos objetivos, y pasar a formar parte de la comunicación y de la estrategia de la campańa.

En América Latina este nuevo enfoque ha penetrado de la mano de Laclau (2005: 5-8), que ha convertido al relato en un marco de agregación de mayorías populares en países como Argentina (Nicardona, 2013), Venezuela (García-Larralde, 2007), Bolivia (Errejón, 2011), Ecuador (Segovia, 2007) o Nicaragua (Nicolella, 2011). Laclau sostiene que la creciente heterogeneidad de la sociedad postmoderna invalida los mensajes marxistas clásicos (los destinados exclusivamente a la clase obrera). Ante la pérdida del marco de referencia tradicional de la izquierda, el relato permite que diferentes sectores con realidades disímiles puedan encontrar su representación en un relato en clave nacional que les permita enfrentarse a una oligarquía dominante. Estos relatos, además, tienen un dueño, un protagonista que enlaza con una figura mítica, una idea-fuerza, un valor o una creencia, encarnado, en un proceso histórico, en un líder-candidato capaz de tender un puente con el pueblo (las mayorías populares). Los ejemplos más representativos son el Chavismo, que estructura un relato donde la soberanía popular ha sido secuestrada por el imperialismo estadounidense y el pueblo

3 El relato tiene la estructura de un cuento: presentación envolvente, nudo o desarrollo intrigante, y desenlace sorprendente.

4 El tiempo de instalación es fundamental en la imposición del relato, siguiendo el esquema de la llamada propaganda de integración de Ellul (Pizarroso, 1993: 33). 
venezolano unge a Hugo Chávez para que restaure la libertad de los ciudadanos y devuelva la riqueza nacional a los pobres; el Kirchnerismo con un relato en el que los gobiernos radicales hundieron a Argentina en la crisis del "Corralito" junto al FMI, pero el matrimonio Kirchner recuperó la soberanía argentina y estabilizó económicamente al país al enfrentarse al poder transnacional financiero y negarse a pagar la deuda; el Evomoralismo con un relato donde la minoría blanca y oligárquica oprimió a la mayoría india y campesina desde el colonialismo, pero al fin un líder indígena y sindicalista como Evo Morales emerge para devolver a los andinos su dignidad y sus derechos sociales, enfrentándose a los poderes oligárquicos e imperialistas; el Correismo con un relato en el que un pequeño país ecuatorial ha sido expoliado por títeres al servicio del imperialismo estadounidense, pero el pueblo al fin ha logrado emanciparse aupando a la Presidencia al líder Rafael Correa, que impulsará una revolución ciudadana, o el Sandinismo que elabora un relato donde el antiguo líder guerrillero Daniel Ortega regresa para salvar al país y volver a comandarlo frente a las oligarquías y al neo-colonialismo. El relato le ańade a ese candidato (o a ese líder) lo que en el modelo anterior le sumaba la defensa de ideas, temas, políticas o valores.

En la última década, el storytelling (Salmon, 2007) se ha consagrado como la técnica que da forma y estructura al relato para que éste pueda ser comunicado y transmitido de una manera breve, sencilla y fácil de comprender por todos los segmentos que forman parte del público objetivo $^{5}$. El storytelling se elabora con la intención de apelar a los sentimientos y emociones a través de contar una narración, una historia, siguiendo la morfología del cuento de Propp (1987). Y es que los ciudadanos quieren oír una historia. El creciente uso del storytelling tiene el objetivo de ofrecer un relato coherente de los candidatos, no una letanía de propuestas o promesas.

5 Esta construcción de relatos que marcan la agenda política ha sido denominada por Salmon (2007: 124), como "narraquía". Dichos relatos son construidos mediante técnicas narrativas, con el fin de utilizarlos como estrategias de comunicación política (relatocracia). 
Hoy en día, frente a la concepción dominante del marketing político tradicional, en donde la agenda temática vertebraba el eje de la competición electoral, surge en América Latina (y no sólo allí) una nueva propuesta que suma el relato y le otorga centralidad en el discurso, incorporando la construcción de imaginarios identitarios y simbólicos, generando climas de opinión, y articulando la comunicación a través de un líder-carismático y de un mito de país ${ }^{6}$.

\section{Las propuestas se fragmentan en el marco de una sociedad postmoderna y digital}

La famosa regla derivada del mundo del marketing comercial denominada "propuesta única de ventas" (conocida como USP por sus siglas en inglés), no se acomoda a las características de las campañas postmodernas. No existe una "propuesta única", sino un entramado de mensajes e ideas que pueden variar dependiendo del momento de la campańa y de las contingencias que en ésta acontezcan (Luque, 1996: 187). Las imágenes, los eslóganes, las frases e ideas, los discursos, se fragmentan. Esta fragmentación se acompaña de una segmentación de los públicos, que es uno de los elementos centrales del nuevo marketing político aplicado en las campańas modernas, especialmente en aquellas que tienen un amplio desarrollo en el medio digital (Barko, 2008: 154). Además, las campañas son ahora más largas que antes, incluso muchos países han ampliado legalmente el periodo de campańa, y eso determina que las "ventas" no se acomoden bien a un solo mensaje, a una sola idea, o desde el punto de vista de la segmentación, a un único público.

6 La agenda mediática sigue siendo válida para infinidad de campańas electorales (especialmente en Estados Unidos y Europa), pero estos nuevos movimientos electorales que han sacudido el mapa político e ideológico en Latinoamérica invitan necesariamente a la reflexión académica, ya que tal vez, se puede estar ante el fin de un paradigma comunicativo anglosajón dominante, y se esté en una nueva coyuntura en la que éste haya de convivir con un nuevo paradigma que centre el eje estratégico en el relato. 
La voracidad de los medios de comunicación, en especial de los audiovisuales, y la presencia cada vez más intensa de las redes sociales, reclama una multiplicidad de imágenes e ideas que fragmenta la propuesta única, y aunque se mantenga un eje predominante, se multiplican las imágenes y los contenidos diferenciados y diferenciadores. Esta fragmentación de las propuestas se traduce en una segmentación de los destinatarios. En el marco de la instalación del relato al que antes se hacía referencia, hay margen para determinar los distintos beneficios (y beneficiarios) de las propuestas, y también los posibles perjuicios (y perjudicados) de las ideas de los competidores. De ahí que la campaña tendrá tantos mensajes e imágenes como públicos prodestinatarios, paradestinatarios y contradestinatarios tenga identificados el partido y/o candidato, produciendo un conjunto diferenciado de propuestas e ideas para cada segmento del electorado (Sánchez y Aguilar, 2004: 94).

La identificación de micro tendencias y la elaboración de sofisticadas bases de datos sobre las poblaciones objetivo, que contienen información tan especifica como estilo de vida, estabilidad económica, comportamientos y actitudes, a la manera del marketing comercial (como en el caso de las técnicas del marketing multinivel), permiten a los equipos de comunicación esbozar una cartografía política completa sobre la que desarrollar el mensaje y la estrategia previamente definida. La base de datos "VoterVault" creada en 1995 por el Partido Republicano en Estados Unidos es un buen ejemplo de este tipo de bases de datos construidas mediante la recopilación de los registros de votantes, la compra de datos comerciales y el uso de técnicas de marketing directo. Esta herramienta alcanzó su madurez con las campañas de 2008 y 2012 de Obama, pues ambas estuvieron centradas en una gran estrategia digital con base en el ya famoso Big Data ${ }^{7}$. Algunos expertos, incluso,

7 Sasha Issenberg, autora del libro The Victory Lab: The Secret Science of Winning Campaigns, publicó en 2012 el artículo "How President Obama's campaign used Big Data to rally individual voters" (http://www.technologyreview.com/featuredstory/509026/how-obamas-team-used-bigdata-to-rally-voters/) en el que describe de manera minuciosa el uso de esta herramienta. Otro documento lo ofrece Moisés Naím, en un artículo en El País (http://internacional.elpais.com/ internacional/2012/11/10/actualidad/1352575076_277451.html), donde reproduce un correo 
empiezan a considerar que el rol de los consultores tradicionales dejará paso a un nuevo perfil: los data crunchers. Estos "devoradores de datos" se dedican, entre otras cosas, a recopilar y analizar paquetes de datos masivos . Los big data, los datos masivos, se refieren a las cosas que se pueden hacer a gran escala, para extraer nuevas percepciones o crear nuevas formas de valor, de tal forma que transforman los mercados, las organizaciones, las relaciones entre los ciudadanos y los gobiernos, etcétera (Mayer-Schönberger y Cukier, 2013: 17).

\section{En épocas de mitos, las elecciones se transforman en plebiscitos}

En las campañas postmodernas, partidos de todo signo, especialmente aquellos de izquierda que ocupan posiciones de poder, han reinventado el mito como argumento para construir (o reconstruir) identidades nacionales o mayorías populares (de clase). El nuevo mito político constituye, de acuerdo con Sorel (2005: 129-146), una sucesión de imágenes (relatos) capaces de evocar instintivamente todos los sentimientos. El mito político moderno es una agregación de principios presentes en las mitologías políticas tradicionales: la construcción del enemigo ("nosotros" y los "otros"); la ilusión por un pasado que fue mejor para "nosotros" (aunque quizá nunca existió); el líder carismático ("el salvador”), o la unidad del pueblo en un destino común. Sorel (2005: 129-146) ańade que los mitos no deben ser valorados con respecto a su sentido de la realidad, sino con respecto a su capacidad para unir en torno a ellos a una masa poblacional que de otra manera estaría desunida y sería heterogénea, sirviendo para "construir una fuerte frontera interna".

electrónico que le mandó un voluntario de la campaña de Obama 2012: "Es muy fácil, y si deseas lo puedes hacer en español y desde tu teléfono móvil. Solo necesitas ir a www.barackobama.com y abrir una cuenta como voluntario. Te darán una lista de nombres y teléfonos, así como información muy concreta sobre cada persona a la que estarás llamando. Puedes llamar a cualquier ciudad en todos los Estados del país (te dicen cuál es la mejor hora) y tener un impacto directo. Yo acabo de convencer a una señora en Virginia para que lleve a sus padres a votar y mi amigo (sentado aquí en la cafetería conmigo) acaba de hablar con un indeciso en Pennsylvania y lo persuadió de votar por Obama". 
En este marco, en las más recientes campañas presidenciales, sobre todo en América Latina, lo que se ha puesto en juego no es un cambio del titular del poder, o la continuidad del mismo, sino la lucha entre el bien y el mal, entre el progreso y el desastre, entre la estabilidad o la guerra. El líder que encarna los principios del mito generado e instalado en la mente de los votantes, proclama que su derrota no significa sólo el fin de un tipo de políticas, sino que con ésta se conjura un proceso histórico, se terminan años de estabilidad, se deja al poder en manos de oligopolios y potencias extranjeras, o se generan las condiciones para un golpe de estado o una guerra civil. Todo es mítico, el resultado de cada elección se expone como el fin de los tiempos, con la derrota de un líder se derrota al pueblo, se cambia el curso de la historia o se fracasa en la construcción del Estado nacional. Esto provoca unas campañas que son más plebiscitos que elecciones, y en las cuáles la lucha por las políticas concretas da paso a una lucha por el futuro, con gran angustia, por otra parte, para los ciudadanos, espectadores de la gran tragedia en que se convierte la arena de competición.

\section{Los atributos del líder (candidato) se imponen a los temas (propuestas) como elemento de diferenciación y posicionamiento en las campańas}

Aunque los temas siguen presentes en la discusión electoral de las campańas actuales, los atributos o cualidades políticas y/o personales percibidas en el candidato, junto a la presencia del relato, son los ejes básicos de la moderna disputa electoral.

La hegemonía del modelo de identificación partidista y/o ideológica en Estados Unidos y Europa hasta mediada la década de 1960, anuló los efectos que los temas y candidatos podían tener sobre la decisión de los electores (Budge et al., 2010: 4-5). Sin embargo, tanto los temas de campańa como la personalidad de los candidatos empezaron a ser factores de peso en la orientación de los votantes coincidiendo con la 
preminencia de los medios de comunicación de masas, especialmente de la televisión, y la presencia de figuras políticas que trascendían las tradicionales líneas divisorias entre los partidos, como el caso de J. F. Kennedy. Este proceso se agudizó a partir de la década de 1980, cuando el marketing político se centra en la personalización de las campañas, aprovechando el auge de figuras como Thatcher o Reagan, capaces de producir rupturas tanto con los marcos y discursos de los adversarios como en los de sus propios partidos ${ }^{8}$.

En este contexto, los atributos o cualidades del candidato, tanto lo qué es como más aun lo que se quiere que los ciudadanos perciban qué es, se convierten hoy en día en el primero de los elementos de comunicación en las campañas electorales. De hecho, la personalización de las campańas se basa en las características personales o cualidades políticas del candidato o líder (autoridad, experiencia, habilidades interpersonales, cualidades morales o éticas, etcétera). Estos atributos del candidato priman sobre los temas, o al menos se intenta que se asocien a los principales ejes temáticos, permitiendo a través de éstos enmarcar y posicionar al candidato en una esfera distintiva y diferenciadora. $Y$ es que el factor de posicionamiento, y por tanto de diferenciación con el resto de competidores, eso que lo hará único, que será el valor para recibir los afectos (y los votos), es clave en la contienda electoral. El objetivo del posicionamiento es ocupar un espacio preferente en la mente de los "clientes" (votantes actuales y/o potenciales). Posicionamiento implica representar una idea diferenciadora como candidato en la mente del votante (Trout y Rivkin, 1996) y supone básicamente: (a) Disponer de una idea simple o concepto que lo diferencie de la competencia; (b) Tener el producto que haga real y creíble esa idea o concepto, y (c) Diseñar el programa para hacer conscientes a los votantes actuales y potenciales de esa diferencia. Este posicionamiento es favorecido en la actualidad por la gran cantidad de mensajes que reciben los electores a

8 Para McAllister (2007: 572), la primera figura política en occidente que se puso por encima del partido en popularidad, generando un fenómeno de adhesión personal, fue probablemente el primer ministro canadiense Pierre Trudeau, en 1968, que fue capaz de atraer el voto de los jóvenes que participaban electoralmente por primera vez con una imagen dinámica y rupturista. 
través de los medios de comunicación, tanto por los tradicionales como por aquellos surgidos a raíz de las nuevas tecnologías.

El proceso de fijación y posicionamiento de los atributos y cualidades del candidato se produce en un contexto en el que coinciden de manera paralela varios procesos: la creciente profesionalización y tecnificación de la política; el debilitamiento de los vínculos entre ciudadanos y partidos (Ohr, 2011: 11-12), o el triunfo de los medios de comunicación audiovisuales, que por su propia naturaleza exigen "personalizar" visualmente características en personajes, lo que favorece centrarse en el candidato en detrimento de las organizaciones (Ohr, 2011: 14). Finalmente, fenómenos político-comunicativos como el de Obama permiten enmarcar el reforzamiento del proceso a partir de los nuevos medios digitales, que acentúan la tendencia a la personalización en candidatos y relatos, y además operan una pareja individuación del votante-usuario, ya no como un mero receptor de imágenes y relatos, sino como un nodo que crea y difunde sus propios contenidos y entabla una relación "personal" con el candidato (Crespo et al., 2011: 215-216).

\section{La imposición de un liderazgo de la visibilidad}

Aunque la irrupción de las nuevas tecnologías de la información y la comunicación, y más recientemente la aparición de las redes sociales, están cambiando el perfil de la comunicación de campańa, hoy sigue siendo fundamental la transmisión que de la misma realiza la televisión ${ }^{9}$. Si un partido y/o candidato pretende estar presente en el imaginario social, es impensable que lo pueda realizar sin el concurso de una estrategia de comunicación televisiva. La capacidad de comunicar los atributos y cualidades de un candidato está en manos de los medios de comunicación, pero especialmente de la televisión. Crear una imagen

9 Un buen ejemplo de la influencia de las telenovelas en la política (en este caso brasileńa) se encuentra en los estudios de Venicio Lima o Carlos Eduardo Lins da Silva compilados en la obra de Skidmore (1993). 
de candidato "fuerte" (Sartori, 1998) se relaciona con la capacidad que éste tenga de gestionar eficientemente sus apariciones televisivas. A los políticos y candidatos se les impone la construcción de un liderazgo de la visibilidad.

Desde las telenovelas hasta las noticias, la televisión está creando hoy en día los marcos para la política ${ }^{10}$. Por esta razón, si el político o el candidato no se adaptan a las pautas informativas del medio televisivo y a la dinámica de la televisión-espectáculo, asume un alto riesgo de quedarse fuera del escenario político que construye el medio audiovisual. Sin éste, es imposible hoy en día posicionarse con garantías de éxito en el espacio público, y menos aún construir con eficacia un relato multimedial que pueda llegar al conjunto de las audiencias, que es la forma postmoderna en la que los políticos se dirigen hoy a sus públicos.

Esta orientación de la política hacia el medio televisivo está muy presente en los regímenes populistas de nuevo cuño (Boas, 2005), como reflejo de una sociedad atomizada y de la existencia de un líder que transforma su presencia en el medio como un reflejo de la opinión de la sociedad, o al menos de una importante parte de ésta. La pantalla de televisión se convierte en el perfecto sustituto de la política de la razón y de la palabra, sustituida en este caso por la imagen y la identificación del público con personajes metapolíticos y mediáticos (Degregori, 2001). Esta dinámica no está exenta de sus críticas. Pierre Bourdieu (1997: 10) considera que la televisión es "un peligro para la política y la democracia”, y Giovanni Sartori (1998) argumenta que la televisión conduce a que la política y la democracia se conviertan en un mero espectáculo.

10 Un buen ejemplo de la influencia de las telenovelas en la política (en este caso brasileńa) se encuentra en los estudios de Venicio Lima o Carlos Eduardo Lins da Silva compilados en la obra de Skidmore (1993). 


\section{El acto público como interacción simbólica entre el candidato y sus seguidores}

Que los candidatos deban estar sí o sí en los medios de comunicación de manera habitual para consolidar su liderazgo, para reforzar su imagen, para mantener o conquistar apoyos, para difundir su visión, para contrarrestar los mensajes de los stakeholders, etcétera, parece casi obvio. Pero esto no implica necesariamente estar en contacto directo con los medios. Si la evolución de la comunicación ha hecho que los medios, en especial los audiovisuales, se hayan convertido en la fuente casi exclusiva de difusión de la imagen, también ha facilitado que el canal de llegada a los mismos se haya diversificado.

En el marco de las campañas electorales, el acto público (televisado/retransmitido), basado principalmente en elementos persuasivos y emotivos, se adecua mejor que muchas otras tácticas a la sociedad del espectáculo, el simulacro y la vídeo-política. El acto público se concibe como una acción comunicativa que reúne los aspectos rituales y míticos más tradicionales de la política, revelándose como la estrategia más eficaz para orientar la interacción simbólica entre el candidato y sus seguidores.

En el marco del acto público, el lenguaje es esencial. Los mensajes, materializados en palabras claves, evocan en la audiencia marcos que representan ideas y generan imágenes con el objetivo de despertar las emociones entre el electorado. El lenguaje se presenta como una herramienta clave: "la mente humana se activa accediendo a los mapas del cerebro mediante el lenguaje" (Castells, 2009: 197). Y si el lenguaje es la puerta de acceso a la mente, para que se produzca la comunicación, "el cerebro y sus percepciones sensoriales necesitan protocolos. Los protocolos más importantes son las metáforas. Nuestro cerebro piensa con metáforas, a las que se puede acceder por el lenguaje" (Castells, 2009: 197).

En este proceso, los marcos adquieren una relevancia crucial como "estructuras mentales que conforman nuestro modo de ver el mun- 
do" (Lakoff, 2006: 17). De ahí que cuando discursivamente se niega un marco, en realidad se está evocando, de manera que, como expresa Lakoff (2006: 6), "cuando hay que discutir con el adversario, no utilices su lenguaje" (su marco). Por ello es de vital importancia emplear un lenguaje distinto al del oponente, porque si se utiliza su lenguaje (su marco), se estarán reforzando sus ideas y entonces el esfuerzo comunicativo del emisor será en vano. Es por todo esto, que en el acto público, como en el resto de herramientas del plan de comunicación, es de vital importancia enmarcar correctamente las ideas y que éstas sean coherentes con la propuesta política e ideológica. Si se realiza ese correcto enmarcado, las ideas evocarán en el cerebro del elector esos marcos conceptuales asociados y mediante el lenguaje se podrán instalar y difundir.

\section{Públicos cada vez más heterogéneos, sociedades cada vez más duales}

En la época de los partidos de masas, éstos se conformaban "por grupos sociales predefinidos de contornos precisos" (Katz y Mair, 2004: 1114). La comunicación de estas formaciones políticas iba destinada a un público objetivo determinado, homogéneo y leal. Para la selección de los segmentos de electores (targets), que podrían ser susceptibles de ser influidos por la comunicación persuasiva de una propuesta política, la sociedad era entonces dividida en clases sociales, grupos etarios, lugares de residencia, identificaciones partidistas latentes, etcétera. De una forma menos sofisticada, los públicos objetivo eran ricos, clases medias o pobres, vivían en grandes ciudades, en áreas urbanas periféricas o en el campo, eran jóvenes, de mediana edad o ancianos, etcétera. Este modelo, basado en compartimentos estancos, se empezaría a poner en cuestión mediada la década de 1960. Diversos factores, fruto del proceso de modernización de las sociedades, como el "desdibujamiento" de las tradicionales líneas de división partidistas y la pérdida de las identidades colectivas; la mejora de las condiciones de vida en el marco de los 
Estados del Bienestar, o la focalización del mensaje político a través de la televisión, comenzaron a forjar un nuevo electorado. En éste, las líneas de división tradicionales se transversalizaron, conformando grupos cada vez más heterogéneos que no respondían a las clásicas divisiones socio-demográficas, socio-económicas y/o socio-políticas.

Ante una sociedad cada vez más fragmentada, la comunicación política tiene serios problemas para lograr un mensaje que, aunque puede llegar a una audiencia más amplia, resulta poco eficaz por la propia heterogeneidad de la misma. Para los partidos políticos y sus candidatos, la solución ha sido aprovechar la dualidad socio-económica que iba imponiéndose en nuestras sociedades a partir de la década de 1980 en Estados Unidos y Gran Bretańa, posteriormente en Europa continental y a partir de 1990 en América Latina, para generar esquemas de comunicación basados en dicotomías excluyentes, en consonancia con los marcos dicotómicos asociados al relato (buenos o malos, favorecedores del proceso de construcción nacional o siervos de los intereses de los grupos de poder, fieles a los ideales de la revolución o amigos del imperialismo yanqui). Estos grupos de héroes y villanos se corresponden con targets muy definidos, más simples, más dicotómicos, que pueden atravesar, y de hecho atraviesan, las tradicionales brechas etarias, socio-económicas o geográficas.

En este marco, el concepto de idea-fuerza ${ }^{11}$ cobra una especial relevancia por su capacidad de condensar el contenido de todo un proyecto político, sintetizando en una frase, un símbolo, un icono o una imagen, todo el significado de una propuesta programática. La idea-fuerza se adapta de manera perfecta a la comunicación postmoderna, enfocándose a la parte emocional del cerebro del elector, sintetizando toda la amplitud del argumento político destinado a un grupo de electores que, aún en su heterogeneidad, comparten o son parte de una de las dos mitades en las que se han ido partiendo las sociedades contemporáneas. Así, el mensaje gana en eficacia, aun cuando su distribución se realice

11 Concepto que introdujo el filósofo Alfred Fouillée (2011) en el siglo XIX y que trataba de explicar ese elemento nuclear y esencial que está en todo proceso de comunicación humana. 
por medios masivos, dado que se dirige a un grupo o segmento de la sociedad concreto, pero amplio, que comparte una visión del mundo que no deriva ya de su pertenencia a un estrato social, territorial, etario o económico determinado, sino a un sector más amplio, identificado por un relato predominante.

\section{El enemigo como eje del relato}

A partir de las primeras décadas del nuevo siglo, se ha comenzado a imponer en el marco de las campańas electorales, y muy especialmente en las de América Latina, una nueva forma de hacer política. Su denominador común son escenarios de competición dominados, o al menos donde se privilegia, la confrontación, el antagonismo y la exclusión. El partido o candidato adversario se convierte en muchos casos en el enemigo. Se reproducen en las campañas los esquemas dicotómicos básicos del denominado mito político, que marca líneas divisorias tajantes entre quienes están al lado del discurso hegemónico, o cuando menos dominante, y quienes se sitúan al "otro lado", y que forman parte, por tanto, del enemigo. Su mera existencia refuerza al mito político y a la idea-fuerza de los partidos-candidatos hegemónicos o dominantes. De hecho, sin la existencia del "lado oscuro", y por tanto de la generación de competiciones de confrontación y antagonismo, el mito político perdería su fuerza comunicacional. Contar con un enemigo visible, aunque sea en muchos casos externo al sistema e incluso simbólico, ayuda a generar la cohesión en torno al mito (al relato) por parte de ciudadanos-electores pertenecientes a segmentos profundamente heterogéneos. El reconocimiento de la existencia de un enemigo común estimula la adhesión y el sentido de pertenencia a un proyecto político. Por eso, en determinadas situaciones, los partidos-candidatos pueden incluso generar de manera artificial conflictos "controlados" que ayuden a significar y visualizar a un enemigo otrora inexistente. Como sentencia Eco (2013: 11), “tener siempre a mano un enemigo sobre el 
que descargar nuestras debilidades o faltas es siempre una ventaja. Y, si ese enemigo no existe, puede que haya que crearlo".

En esta construcción del enemigo juega un papel fundamental la emotividad. Numerosas investigaciones indican que las emociones son más fuertes que las ideas, la lógica y la razón ${ }^{12}$, y que cuando hay conflicto entre la razón y la emoción, la segunda suele primar. Damasio (1996: 11) sostiene que las emociones influyen más en la conducta de los individuos que los mismos procesos racionales, y afirma que no todas las acciones individuales son producto de una deliberación racional. Westen (2007), al analizar las reacciones neurológicas de los votantes, demostró que quien ya está decidido electoralmente, busca razones para sostener conclusiones falsas, deduciendo que el cerebro político es un cerebro emocional. Esto no significa desestimar la influencia de los aspectos programáticos en la toma de decisiones, pero éstos pasan a tener una importancia secundaria. Por tanto, los partidos y/o candidatos que se centran en asuntos (temas), pensando que los electores deciden su voto desapasionadamente, tienen serios riesgos de no incidir en la agenda política y/o electoral. En realidad, los electores se decantan hacia el partido o candidato, hacia el relato o la idea-fuerza en términos comunicacionales, que le provoca las emociones (sentimientos) adecuadas ${ }^{13}$, no al que presenta los mejores argumentos (razones). Para argumentar su decisión política o la orientación de su voto hacia un determinado partido y/o candidato, el elector se afana en encontrar razones sólidas que permitan dar coherencia a la misma (Crespo et al., 2011: 116), no siendo irrelevante la información "racional" para dar consistencia a las emociones que en realidad guían su acción. Incluso el propio voto ideológico no necesita de una argumentación avanzada, sino que se sustenta

12 Javier del Rey Morató (2007: 56) afirma que "la comunicación persuasiva se sirve de dos vías para conseguir su propósito. La vía racional se rige por el pensamiento secundario, por la lógica y el argumento. La vía emotiva se rige por el pensamiento primario, el pensamiento asociativo, y no actúa por la lógica ni por la fuerza persuasiva del argumento sino por asociación simbólica".

13 Para Castells (2009: 203), "las emociones más importantes para el comportamiento político son el entusiasmo (y su opuesto, la depresión) y el miedo (y su contrario, la calma)”. 
en las emociones y los sentimientos que se generan a partir del partido y/o candidato (Crespo et al., 2011: 121).

La creación del enemigo y la emotividad como fundamento del comportamiento político, adquieren su mayor visibilidad en el campo de las campañas con el ejercicio de la comunicación política negativa. Las campañas electorales negativas revelan la considerable influencia de las emociones y de los sentimientos, en este caso de negatividad, en la consciencia del elector (García Beaudoux et al., 2005: 209-210). Los ciudadanos perciben y reaccionan en términos electorales ante las amenazas, los miedos y los peligros de forma inmediata, casi inconsciente, y su capacidad de atención y retención de los mensajes aumenta exponencialmente cuando éstos se perciben con una carga negativa. Estos mensajes negativos son vistos como una amenaza para la consecución de emociones positivas, aquellas más perseguidas por los ciudadanos, motivando al elector a votar para evitar los efectos negativos que provocaría un candidato y/o partido percibido como "amenazante". Y esto tiene evidentemente consecuencias tanto estratégicas como electorales. Los mensajes emotivos de carácter negativo ayudan en la movilización de los electorados menos participativos y también entre los ciudadanos indecisos. O como señala Castells (2009: 204), "el miedo erosiona el apoyo al contrario y aumenta la importancia del voto entre aquellos candidatos a los que inquietó".

\section{La tecnología entra en campaña}

La televisión sigue siendo el medio más relevante para la comunicación política. La prevalencia de los mensajes emitidos por este medio, en términos de penetración y memorización para los ciudadanos, la convierten en herramienta central en la planificación de la mayor parte de las campañas. A pesar de ello, las nuevas tecnologías de la información y la comunicación, entre las que destacan Internet y las redes sociales, forman ahora parte ineludible en la comunicación de partidos y can- 
didatos. El uso de las plataformas on line en las campańas renuevan y potencian las tradicionales técnicas de marketing directo, que parecían haberse quedado obsoletas con la hegemonía de medios de comunicación como la prensa, la radio y, sobre todo, la televisión. El uso de Internet permite un revival postmoderno de la comunicación cara a cara, del uso del marketing telefónico, del mailing y de muchas otras técnicas tradicionales de la comunicación de antaño entre partidos y electores. Eso sí, esas técnicas, rejuvenecidas por Internet, permiten en esta ocasión la posibilidad de un retorno inmediato desde el receptor al emisor y la capacidad de contagiar los mensajes a un amplio conjunto de ciudadanos, asumiendo ellos mismos el rol de emisores, transmisores y receptores de un continuo sinfín de mensajes. Son comunidades en red, donde cada una de las personas se conecta entre sí, dialogan entre ellos e influyen con su comunicación en otro tipo de público más diverso (Fernández Torres y Paniagua Rojano, 2012: 130).

La moderna comunicación política adquiere a un ritmo vertiginoso un fuerte influjo tecnológico que, independientemente de convertirse o no en una herramienta central de la comunicación de campaña, produce un cambio sustantivo en la praxis política. Y como la comunicación, vía este impacto tecnológico, está mutando aceleradamente, así se transforma también la forma de hacer política. En especial porque el uso de Internet y de las redes sociales tiene un impacto cada vez mayor en la creación de clima político y, por tanto, en la formación de la opinión pública. Y a diferencia de los medios de comunicación tradicionales, en este espacio virtual los partidos y/o candidatos pierden el control, o al menos la capacidad de regulación, de los mensajes y las opiniones. Éstos se generan de manera más espontánea, menos dirigida, pasando de una situación de verticalidad unidireccional a una de horizontalidad bidireccional. Es por ello que la política en el siglo de Internet se debe adaptar a unos nuevos códigos, pautas y rutinas de comunicación, como ya lo hizo con el surgimiento primero de los periódicos de distribución masiva, o tras la aparición de la radio, y aún más tras el auge de la televisión como fenómeno de masas. 
En la actualidad, la opinión no se construye sólo a través de lo que dicen los medios, sino a través de la interacción con ellos e incluso al margen de los mismos (García Galindo, 2010). Con las nuevas tecnologías de la información y la comunicación, la relación unidireccional se debilita en favor de una comunión entre el emisor y el receptor, los cuales tienen la misma capacidad para intercambiar mensajes. El receptor no sólo es consumidor, también es creador y generador de ideas, espacios, productos y contenidos (Crespo et al., 2011:215). En este contexto, surgen activistas on line que aprovechando estos nuevos recursos y modernizando la comunicación política tradicional organizan comunidades virtuales que se generan alrededor de afinidades ideológicas, vínculos políticos o preocupaciones compartidas sobre un tema. En estas ágoras del ciberespacio, la información se distribuye horizontalmente, atendiendo a los temas que les preocupan, distribuyendo la información necesaria para tomar conciencia o debatir sobre los mismos, proveyendo de argumentos para unificar criterios o posiciones al respecto, e incluso siendo capaces de colocar éstas como relevantes u oportunas en la agenda de los medios tradicionales o en los mensajes de los partidos y/o candidatos.

Es por ello que uno de los objetivos claves de la moderna comunicación política digital es crear una comunidad. De esta son partícipes y "socios" no sólo los militantes partidistas o los simpatizantes de un líder o candidato, sino también sectores y grupos más amplios que le dan su apoyo. A todos ellos, la comunidad les proporciona la información (argumental-racional, pero también simbólica-emocional) directamente a través de las redes sociales (incluso de manera previa que a los medios de comunicación tradicionales); les ofrece el desarrollo de actos y eventos de carácter político, e incluso les permite organizar sus propias actividades y acciones concretas, anunciándolas, por ejemplo, en Google Maps para informar sobre el lugar de celebración de las fiestas o reuniones propagandísticas, etcétera. Esto fue lo que aprovecharon los estrategas de la campańa electoral de Barack Obama en 2008: la integración de la campaña en el mundo on line y la transformación de 
estas acciones al mundo off line ${ }^{14}$ (Crespo et al., 2011: 217).

Por tanto, son la interactividad y la participación los elementos clave en la comunicación política digital del nuevo siglo. Y esto afecta a los públicos a los que ésta va dirigida. El nuevo targeting digital se basa en un conocimiento casi exhaustivo de las necesidades (problemas, aspiraciones, esperanzas, temores) del elector moderno, en una mayor personalización del mensaje y la forja de vínculos de confianza y de comunidad que sirvan como potenciadores virales del mensaje. La persuasión de las "masas" queda obsoleta en el escenario virtual, siendo sustituida por una comunicación individual. "La base de la comunicación de la sociedad red es la web global de redes de comunicación horizontal que incluyen el intercambio multimodal de mensajes interactivos de muchos a muchos" (Castells, 2009: 203).

A pesar de todo ello, las nuevas tecnologías de la información y la comunicación, y en especial Internet y las redes sociales, no deben verse como sustitutas de los medios tradicionales, sino más bien como herramientas convergentes y complementarias. Hoy por hoy, los medios tradicionales, tanto en su rol de formadores de agenda y opinión, como de generadores y transmisores de imagen, ocupan una posición central en la comunicación de campańa. Aunque en muchas de éstas el papel de las NTICs esté siendo relevante, en ninguna su sola utilización ha dado resultados positivos para los candidatos que desde éstas han competido. El posicionamiento de un tema en la agenda y el de un candidato en las preferencias de los electores pasa, hoy en día, por seguir poniendo a los medios tradicionales en el centro de la estrategia de comunicación. Es cierto que estos nuevos instrumentos de comunicación y su impacto en la forma de hacer política, "pueden llegar a equilibrar o compensar el poder actual de los media, de los grupos de presión o de los partidos" (Subirats, 2003: 110); incluso las redes sociales pueden posibilitar el contacto directo con la clase política y romper el monopolio que deten-

14 Dentro de la comunidad existía incluso un ranking de implicación, llamado el "activity index de MyBO.com", donde los miembros que realizaran más acciones de campaña, como escribir en blogs, subir vídeos a la red o llamar a amigos para animarles a venir a un acto, ascenderían en el ranking (Crespo et al., 2011: 217). 
tan los medios tradicionales en la formación de la opinión pública y en la construcción de la agenda mediática. Sin embargo, hay que ser moderados ante el fenómeno que supone la comunicación política digital y el impacto que ésta produce. Más que producir una sustitución de los medios tradicionales, la nueva comunicación digital apunta más hacia caminos convergentes, como una herramienta para la construcción de un ágora donde se discuten los temas que primordialmente han sido destacados por los medios convencionales (García Galindo, 2010), o para nutrir a los anteriores de noticias, informaciones y opiniones que complementan su agenda.

\section{A modo de síntesis}

En la comunicación política, y más específicamente en la desarrollada en el marco de las campańas electorales, ha acontecido durante esta última década un fuerte proceso de transformación. Los cambios más notables se han dado alrededor de tres aspectos.

En primer lugar, la centralidad que ha adquirido el líder-candidato como vertebrador del mensaje de campaña. Éste ha pasado a convertirse en un factor decisivo de voto. En los cada vez más frecuentes contextos de una política fuertemente personalizada, el mensaje hacia los electores es emitido casi de manera exclusiva a través de los líderes, que además de ser portadores de la oferta electoral del partido, se esfuerzan por hacer ésta creíble y ellos mismos confiables.

En segundo lugar, la irrupción de la tecnología como una herramienta que acompańa todo el proceso de elaboración, transmisión y retroalimentación del mensaje, liberando a éste de la servidumbre de los canales y medios de comunicación tradicionales. La comunicación política ha abierto el camino no sólo para la integración de las acciones de campaña en el mundo digital, sino también para la transformación de estas acciones al mundo offline. 
Y, en tercer lugar, la nueva comunicación política se ha caracterizado por el paso de una estrategia basada en la construcción de argumentos racionales, a una narrativa de campańa centrada en el relato emocional. La comunicación persuasiva no radica ya en la satisfacción de las necesidades objetivas de los electores, sino en la construcción de relatos emotivos, apasionados, míticos. Y es que los ciudadanos quieren oír una historia, no una letanía de propuestas o promesas.

Estos cambios en la comunicación política son fruto de unos nuevos tipos de electores, que no responden comunicacionalmente a los viejos estereotipos de fácil segmentación. La modernización de los públicos ha afectado al desarrollo de las estrategias de competición de los partidos. La vieja forma de hacer política no ha desaparecido, pero ha dejado de ser hegemónica. Y en este contexto, se pueden identificar al menos tres tendencias.

La primera. El control del mensaje por los partidos se resquebrajará, y los liderazgos impondrán su presencia por encima de los temas puramente partidistas. Las cualidades tanto personales, como en menor medida políticas, asociadas al líder, primarán sobre los temas, permitiendo a través de ésas enmarcar y posicionar al candidato en una esfera distintiva y diferenciadora.

La segunda. Los medios de comunicación tradicionales se adaptarán a las pautas informativas (inmediatez, caducidad, viralidad, etcétera) de la comunicación digital. En el marco de las campañas electorales, la información de los medios tradicionales responderá a la sociedad del espectáculo, el simulacro y la vídeo-política que impone el marco de la comunicación digital.

Y la tercera. El mensaje de campaña dejará de ser monolítico. Cada campaña tendrá tantos mensajes e imágenes como tipos de públicos tenga identificados el partido, produciendo un conjunto heterogéneo y multisignificativo de propuestas para satisfacer a cada segmento del electorado. La coherencia del mensaje no vendrá determinada por su contenido, diverso, sino por la existencia de una idea-fuerza enfocada a la parte emocional del cerebro del elector, sintetizando toda la amplitud 
del argumento político destinado a un grupo de electores que, aún en su heterogeneidad, compartirán o serán participes de una idea simple, pero común.

\section{Bibliografía}

Barko Germany, J. (2009). “The Online Revolution,” en D.W. Johnson (comp.), Campaigning for President 2008: Strategy and Tactics, New Voices and New Techniques. New York: Routledge.

Bauman, Z. (2002). Modernidad líquida. Buenos Aires: FCE.

Boas, T. (2005). "Television and Neopopulism in Latin America: Media Effects in Brazil and Peru", en Latin American Research Review, vol. 40, no 2 (págs. 27-50).

Bourdieu, P. (1997). Sobre la televisión. Barcelona: Anagrama.

Budge, I., I. Crewe y D. Farlie (2010). Party Identification and Beyond: Representations of Voting and Party Competition. ECPR Press.

Canel, M.J. (2006). Comunicación política: Una guía para su estudio y práctica. Madrid: Tecnos.

Castells, M. (2009). Comunicación y Poder. Madrid: Alianza Editorial. Crespo, I., A. Garrido, I. Carletta, y M. Riorda (2011). Manual de comunicación politica y estrategias de campaña. Candidatos, medios y electores en una nueva era. Buenos Aires: Biblos.

Crespo, I. e I. Carletta (2013). "Liderazgo y estrategias de comunicación en las campañas electorales en América Latina”, en I. Crespo y J. del Rey (eds.), Comunicación Politica \& Campañas Electorales en América Latina. Buenos Aires: Biblos (págs. 85-104).

Dader, J.L. (1990). "La personificación de la política", en A. Muñoz, C. Manzón, J.I. Rospir y J.L. Dader (eds.), Opinión Pública y Comunicación Política. Madrid: Edema.

Damasio, A. (1996). El error de Descartes. Santiago de Chile: Andres Bello.

Degregori, C.I. (2001). La década de la antipolítica. Lima: IEP. 
Eco, U. (2013). Construir al enemigo. Barcelona: Lumen.

Errejón Galván, Í. (2011). La hegemonía del MAS en Bolivia. Barcelona: El Viejo Topo (págs. 111-141).

Fernández Torres, J. y F.J. Paniagua Rojano (2012). "El poder de las redes sociales en la política y en los movimientos sociales", en R. Cotarelo e I. Crespo (eds.), La Comunicación Política y las Nuevas Tecnologias. Madrid: Catarata (págs. 130-150).

Fouillée, A. (2011). La morale des idée-forces. París: Nabu-Press.

García Beaudoux, V., O. D’Adamo y G. Slavinsky (2005). Comunicación politica y campañas electorales: estrategias en elecciones presidenciales. Barcelona: Gedisa.

García Galindo, J.A. (2010). "La opinión pública en la sociedad de la información”, en Brocar: Cuadernos de Investigación Histórica, no 34 (págs.273-288).

García Jiménez, L. (2010). "Y el protagonista es el candidato: la personalización como enfoque en comunicación política”, en R. Zamora (coord.), El Candidato Marca. Cómo Gestionar la Imagen del Lider Político. Madrid: Fragua.

Gómez, J. C., A. Pacheco, J. Turbay, y V. Matiz (2006). "La personalización en la política: una práctica a prueba de reformas", en Palabra Clave 9, $\mathrm{n}^{\circ} 2$ (págs. 53-65).

Guerrero García, J. y M.A. Manzano Fernández (2013). "La excelencia en el liderazgo político 2.0", en I. Crespo y J. del Rey (eds.), Comunicación Política \& Campañas Electorales en América Latina. Buenos Aires: Biblos (págs. 69-84).

Katz, R.S. y P. Mair (2004). "El partido cartel”, en Zona Abierta, no 108/109, Madrid (págs. 9-39).

Laclau, E. (2005). La Razón Populista. Buenos Aires: Fondo de Cultura Económica.

Lakoff, G. (2006). No pienses en un elefante. Madrid: Editorial Complutense.

Luque, T. (1996). Marketing Politico: un análisis de intercambio politico. Barcelona: Ariel. 
Martín Salgado, L. (2002). Marketing politico: ciencia y arte de la persuasión. Barcelona: Paidos.

Mayer-Schönberger, V. y K. Cukier (2013). Big data. La revolución de los datos masivos. Madrid: Turner.

McAllister, I. (2007). "The personalization of politics”, en R.J. Dalton y H.D. Klingeman (eds.), The Oxford Handbook of Political Behavior. Oxford: Handbooks Online.

Mouffe, Ch. (2007). En torno a lo político. Buenos Aires: Fondo de Cultura Económica.

Ohr, D. (2011). "Changing patterns in political communication", en K. Aarts, A. Blais y H. Schmitt (eds.), Political Leaders and Democratic Elections. Oxford: Oxford University Press.

Pizarroso, A. (1993). Historia de la propaganda: notas para un estudio de la propaganda politica y de guerra. Madrid: Eudema.

Propp, V. (1987). Morfología del cuento. Madrid: Fundamentos.

Rey Morató, J. (2007). Comunicación politica, internet y campañas electorales. Madrid:Tecnos.

Salmon, Ch. (2007). Storytelling: la máquina de fabricar historias y formatear las mentes. Barcelona: Península.

Sánchez Galicia, J. (2010). Treinta claves para entender el poder. Léxico para la nueva comunicación politica. México: Piso 15 Editores.

Sánchez Galicia, J. y E. Aguilar (2004). Razones de Voto: Manual de Comunicación Electoral. México: Instituto de Comunicación Política.

Sánchez Medero, R. (2009). "La comunicación política española, ¿un modelo propio o una adaptación del modelo estadounidense?”, en Revista de Ciencias Sociales, vol. 15, no 1 (págs. 9-23).

Sartori, G. (1998). Homo videns. La sociedad teledirigida. Madrid: Taurus.

Skidmore, T.E. (ed.) (1993). Television, Politics and the Transition to Democracy in Latin America. Washington/Baltimore: The Woodrow Wilson Center Press/The Johns Hopkins University Press.

Sorel, G. (2005). Reflexiones sobre la violencia. Barcelona: Alianza Editorial. 
Subirats, J. (2003). "Dilemas de una relación inevitable: innovación democrática y tecnologías de la información y de la comunicación", en I. Crespo, ed., El estudio de la politica: problemas y horizontes, Madrid: Thomson Civitas (págs. 109-140).

Trout, J. y S. Rivkin (1996). El nuevo posicionamiento. México: Mc Graw-Hill.

Westen, D. (2007). The Political Brain. The Role of Emotion in Deciding the Fate of the Nation. Nueva York: Public Affairs.

Referencias electrónicas

García-Larralde, H. (2007). Patria, socialismo o muerte. Disponible en: http://analitica.com/va/politica/opinion/8189518.asp

Issenberg, S. (2012). "How President Obama's campaign used Big Data to rally individual voters". Disponible en:

http://www.technologyreview.com/featuredstory/509026/howobamas-team-used-big-data-to-rally-voters/

Naím, M. (2012). "Obama y sus sorpresas". Disponible en:

http://internacional.elpais.com/internacional/2012/11/10/ actualidad/1352575076_277451.html

Nicolella, A. (2011). Populismo, sandinismo y democracia. Disponible en: http://magazineobservador.blogspot.com.es/2011/10/sandinismo-populismo-y-democracia.html

Nicardona, J.I. (2013). Diez años de kirchnnerismo: la década ganada. Disponible en: http://panoramanegro.com.ar/los-10-anos-del-kirchnerismo-la-decada-ganada-por-los-de-siempre/

Segovia Baus, F. (2007). La patria como sentido. Disponible en:

http://periodismociudadano-ecuador.blogspot.com.es/2007/08/ la-patria-como-sentido.html 